\title{
Communication
}

\section{Development of Liquid Solder Resist Based on Polyimide}

\author{
Nobuo Matsumura, Akira Shimada, Keiko Yamanaka \\ Electronic \& Imaging Materials Res. Labs., Toray Industries, Inc. \\ 1-2, Sonoyama 3-chome, Otsu, Shiga 520-0842 Japan
}

Keywords : polyimides, flexible printed circuit board(FPC), coverlay

\section{Introduction}

Flexible Printed Circuit Board(FPC) is a useful for microelectronic devices such as handy phones, mobile audio players and mobile personal computers. Usually surface of FPC is protected by a solder resist from solder and oxidation. The resist is specifically designed to both protect the surface tracks and prevent solder bridges and oxidation during soldering.

Recently patterning pitch between wiring becomes very fine. Especially, in the COF tape package for Flat Panel Display, patterning pitch has narrow below 25um.[1-3] Solder resist is required to be enough electro resistivity as well as low warpage of COF. In addition chemical resistance, flexibility, thermal stability and high adhesion of coating is absolutely imperative.

Conventional solder resist is composed of epoxy resin. The materials do not have enough electro resistivity at such a fine feature size. [4]

To meet the requirements, we designed a new polyimide base solder resist.

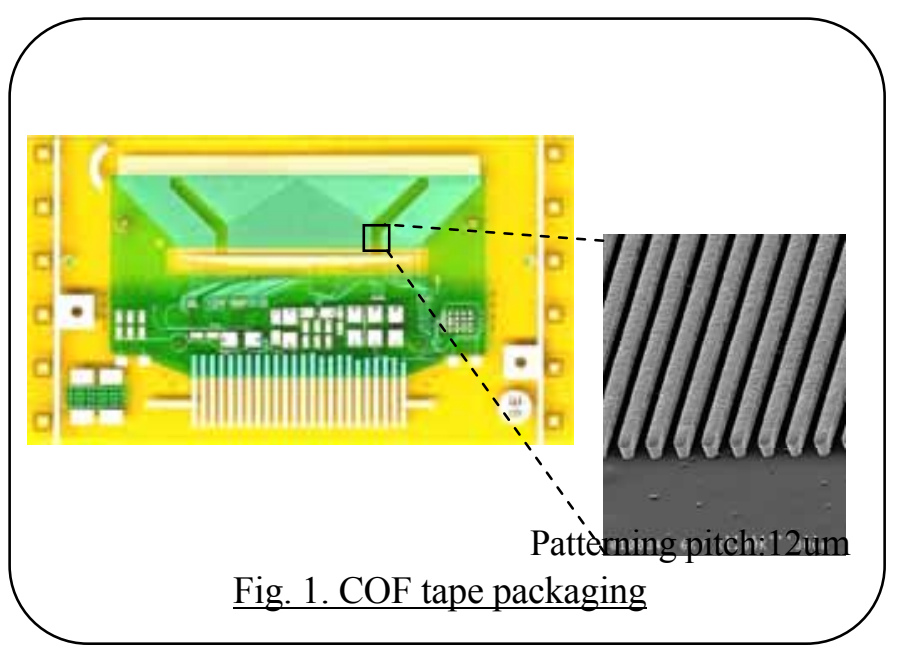

\section{Experimental}

2.1 Synthesis of organic soluble low modulus polyimides.

Figure 2 shows polymerization of organic soluble low modulus polyimide.

A typical procedure is as follows: in a 4-necked flask, diamines were completely dissolved in $\mathrm{Y}$ -butyrolactone in a dry nitrogen atmosphere at $60{ }^{\circ} \mathrm{C}$. To this solution, tetracarboxylic anhydrides were added and reaction for 1 hour. Then heated at 180 ${ }^{\circ} \mathrm{C}$ for $2 \mathrm{~h}$.

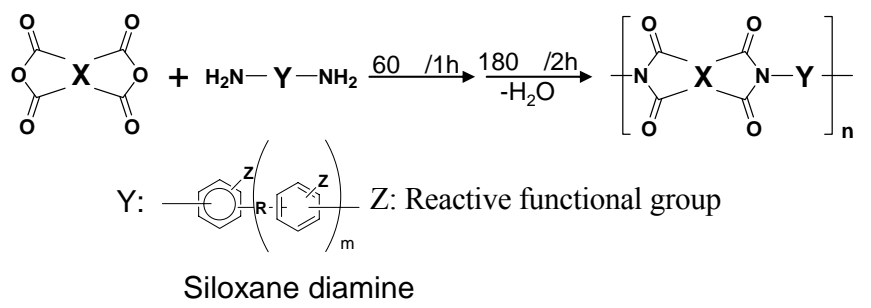

Fig. 2. Polymerization of organic soluble - low modulus polyimide.

\subsection{Preparation of solder resist composition}

Polyimide and other ingredients such as cross-linker were mixed together with $\mathrm{Y}$ -butyrolactone. Then inorganic filler was added to the solution by option.

\subsection{Coating process}

The solder resist composition was coated on Kapton ${ }^{\circledR}$ by screen printing method.

Then coating film was dried in convection oven at $120^{\circ} \mathrm{C}$ for $30 \mathrm{~min}$.

\subsection{Electro migration stability(HHBT test)}

The solder resist composition was coated on FPC 
with comb $\mathrm{Cu}$ pattern (pattern pitch is 20um). The coated sample was cured at $120 \mathrm{C}$ for $60 \mathrm{~min}$. Then the electro migration stability was measured by using ESPEC AEI-020-P. Electrical resistivity was monitored under $85^{\circ} \mathrm{C} 85 \% \mathrm{RH}$ atmosphere applied at $60 \mathrm{~V}$.

\subsection{Chemical resistance}

The solder resist material was immersed and measured the weight loss. Chemical resistance was determined by the weight loss.

\subsection{Flexural endurance}

A $20 \mu \mathrm{m}$ thick film of solder reisit composition on Kapton ${ }^{\circledR}$ film was prepared by coating with screen printing method, drying in convection oven at $120^{\circ} \mathrm{C}$ for $30 \mathrm{~min}$.

The obtained film was cut being size about $50 \mathrm{~mm}$ in length and $10 \mathrm{~mm}$ in width. This sample was bent by $180^{\circ}$.

After bent 10 times, the presence of the crack was observed.

\subsection{Curl evaluation}

A $20 \mu \mathrm{m}$ thick photosensitive polyimide resin

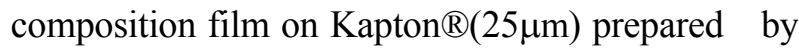
the method described in the 2.3.

The obtained film was cut being size about $50 \mathrm{~mm}$ in length and $50 \mathrm{~mm}$ in width.

This sample was put on the horizontal place, and the height of the highest place was measured.

\subsection{Solder heat resistance}

The $20 \mu \mathrm{m}$ thick film on copper foil prepared by the method described in the above-mentioned was left under the atmosphere of $23{ }^{\circ} \mathrm{C}$ in temperature, $50 \% \mathrm{RH}$ in humidity for 24 hours. Then the sample was floated on solder bath at $300{ }^{\circ} \mathrm{C}$ for $10 \mathrm{sec}$.

After $10 \mathrm{sec}$ floated, the presence of the crack, peeling or swelling was observed.

\section{Results and discussion}

\subsection{Polyimide design}

We designed polyimide structure to show low modulus to $1 \mathrm{GPa}$ or less. However, glass transition temperature ( $\mathrm{Tg}$ ) of the low modulus polyimide is less than 90C. The polyimide itself does not show enough electro migration resistance due to its low $\mathrm{Tg}$ (fig.3). It is thought that molecular motion of the polyimide makes low electro migration resistance during HHBT test. As shown in figure 4, copper ion moved at the base film-solder resist interface during HHBT test.

\subsection{Solder resist design}

To obtain good electro migration resistance, we investigated various types of cross linker which gave high Tg to the composition. Those results were summarized in table 1. Some of the cross linkers shows good electro migration due to its high $\mathrm{Tg}$.

The cross linker gave good chemical resistance as well as high $\mathrm{Tg}$ to solder resist.

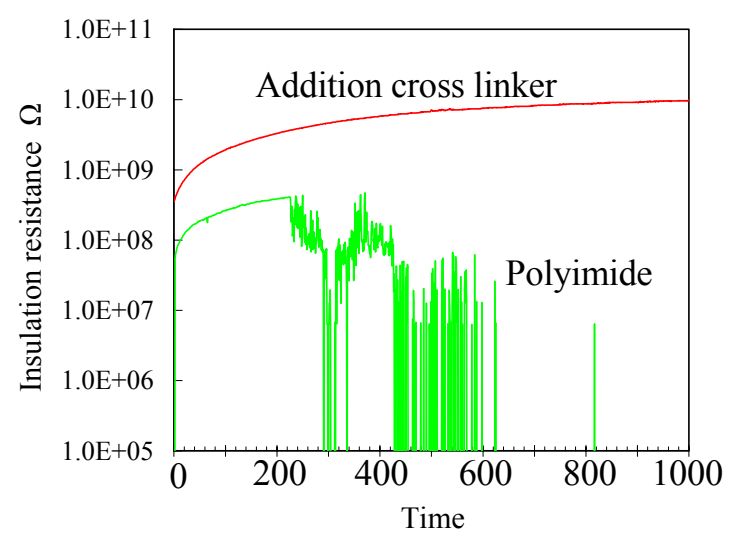

Fig. 3. HHBT test results of polyimide solder resists

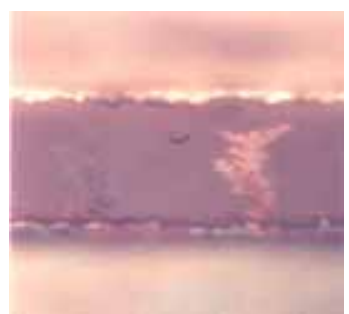

Fig. 4. Metal migration of polyimide solder resist after HHBT test

Table. 1. Insulating resistance of low modulus polyimide and composition

\begin{tabular}{|c|c|c|c|}
\hline Cross linker & Modulus $(\mathrm{GPa})$ & $\mathrm{Tg}\left({ }^{\circ} \mathrm{C}\right)$ & HHBT result \\
\hline Nothing & 1.8 & 86 & $400 \mathrm{~h} \mathrm{NG}$ \\
\hline Addition & 1.9 & 108 & $1000 \mathrm{~h} \mathrm{OK}$ \\
\hline
\end{tabular}

3.3 Mechanical properties and heat resistance

The solder resist composition has strong flexural endurance and low stress with good chemical resistance shown in table 2 as well as good electro migration.

Table. 2. Properties of polyimide based solder resist

\begin{tabular}{|l|c|l|l|c|}
\hline Items & $\begin{array}{c}\text { Chemical } \\
\text { resistance }\end{array}$ & $\begin{array}{l}\text { Flexural } \\
\text { endurance }\end{array}$ & Curl & $\begin{array}{l}\text { Solder Heat } \\
\text { Resistance }\end{array}$ \\
\hline Result & $\begin{array}{c}\mathbf{0 \%} \\
\text { Acetone } \\
\text { Weight } \\
\text { loss }\end{array}$ & $\begin{array}{c}\text { More than } 10 \\
\text { Times } \\
\left(180^{\circ} \text { bent }\right)\end{array}$ & $\mathbf{0 m m}$ & $300^{\circ} \mathrm{C}$ \\
\hline
\end{tabular}

\section{Conclusion}

We developed new polyimide based solder resist which shows good electro migration and low curvature as well as good thermal resistance for very fine feature size. 


\section{Reference}

1. A. Chinda, Journal of Japan Institute of Electronics Packaging, 7(2004)386-390

2. S. Kurihara, Electronic Packaging Technology, 25(2009.3)22-26
3. Semiconductor Materials Outlook 2007, Electronic Journal, (2007)330-338

4. Japan Jisso Technology Roadmap 2007, Japan Electronics \& Information Technology Industries Association, (2007)297-301 